\title{
Article
}

\section{Beyond Bergson: the ontology of togetherness}

Fell, Elena Vladimirovna

Available at http://clok.uclan.ac.uk/7443/

Fell, Elena Vladimirovna (2009) Beyond Bergson: the ontology of togetherness. Empedocles European Journal for the Philosophy of Communication, 1 (1). pp. 9-25. ISSN 1757-1952

It is advisable to refer to the publisher's version if you intend to cite from the work. http://dx.doi.org/10.1386/ejpc.1.1.9/1

For more information about UCLan's research in this area go to http://www.uclan.ac.uk/researchgroups/ and search for < name of research Group>.

For information about Research generally at UCLan please go to http://www.uclan.ac.uk/research/

All outputs in CLoK are protected by Intellectual Property Rights law, including Copyright law. Copyright, IPR and Moral Rights for the works on this site are retained by the individual authors and/or other copyright owners. Terms and conditions for use of this material are defined in the policies page.

\section{CLoK}

Central Lancashire online Knowledge www.clok.uclan.ac.uk

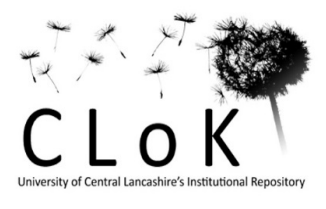




\section{Beyond Bergson: the ontology of togetherness}

Bergson does not have a theory of communication per se but his views on communication can be extracted from his ontology and epistemology. These views may account for some apparent failures of communication - conflicts, loneliness, hostility - and suggest a way out towards better and more harmonious intersubjective relations.

Bergson claims that we misunderstand reality in general and each other in particular. Instead of trying to grasp human nature directly in intuition we analyse its being and create a distorted view of one another. If we were able to conceive human self as it is, we would see it as duration and may be able to reach the state of an open society where people's love towards one another is ontologically backed by their epistemological openness towards each other's being.

However, the Bergsonian theory of duration and intuition, promising to resolve the difficulties of communication, reasserts these difficulties metaphysically. The idea of duration entails the impossibility of accessing it from outside, as the genuine view of it is only possible from within. This paper, instead of trying to salvage a model of communication where people strive to intuit each other's uniqueness, locates intuition in the very act of communication. Bergson himself finds intuition in artistic creation where the artist and spectators communicate by intuiting a common object without learning any personal details about each other. We find that communication is itself duration and that the communicating participants are heterogeneous elements of that duration. As such they are subservient to the act of communication that displays features of autonomous existence. Our model of communication, albeit accepting the impenetrability of one's person for a complete intelligent penetration from outside, allows for the partial fusion of minds engaged in the same act of communication and negotiating the same subject matter. 


\section{The solitude of selfhood: demonstration of analysis and intuition}

Bergson distinguishes two ways in which we can be acquainted with the world and people in it: we can either immerse ourselves in their being, sympathising with them and grasping their true nature or we can observe them from outside, analyse what we perceive and reconstruct the whole object using the fragmented information collected along the way. The view from inside, which Bergson calls intuition, is able to give us an instant and simple vision of infinitely complex reality.

Regretfully, we most often exercise the other approach and, remaining outside things and beings, distort reality and modify it according to our practical requirements. According to Bergson, reality is dynamic, diverse and abundant, but we divide it up mentally into stable and static fragments that our mind is capable of grasping and, when these fragments are rearranged again to make a compete picture, we end up with a one-sided, simplified and hence false representation of reality. When we communicate, we do not address people as they are but as they appear through the prism of our rational analytical interpretation. The real person is out of our reach, so no wonder our communications entail misunderstandings and conflicts. If instead we could master and practice intuition, we would gain an insight into another person's being, an insight that would bring along mutual understanding and mutual sympathy.

In order to demonstrate the difference between intuition that is faithful to the fulsome and vibrant flow of reality and analysis that alters and simplifies it, I will compare two literary texts that could be said to exemplify these methods. In one of them events are presented in an obviously fallacious manner, exaggerating the work of analysis. The other endeavours to offer a matter-of-fact, realistic and detailed account of the events as they may have happened for real, thus exemplifying the tendency to intuit.

The texts in question, Three Musketeers by Alexander Dumas and The Chronicle of the Reign of Charles IX by Prosper Mérimée, have similar storylines. In both narratives young men (d'Artagnan and George Mergy respectively), albeit separated by some two hundred years of the history of Europe, are involved in adventures that revolve around France and the French court. The authors often put their heroes' lives in danger, but whereas reading about d'Artagnan we may feel thrilled and excited, Mergy's predicaments are more likely to make us feel troubled and uneasy, as predicaments actually do. In the swift and exhilarating narrative of Three Musketeers we read: 
[T]he gentleman drew his sword and swooped upon d'Artagnan; but he had a strong opponent to contend with.

In three seconds, d'Artagnan had given him three strokes of the sword, saying at each stroke:

"One for Athos, one for Porthos, one for Aramis!"

At the third stroke, the gentleman fell in a heap.

D'Artagnan thought he was dead, or at least unconscious, and went up to him to take the order; but just as he reached out to search him, the wounded man, who had not let go of his sword, thrust the point into his chest, saying:

"And one for you!"

"And one for me! Saving the best for last!" d'Artagnan cried, furious, and pinned him to the ground with a fourth stroke through the stomach.

This time the gentleman closed his eyes and passed out.

D'Artagnan rummaged in the pocket where he had seen him put the order of passage, and took it. It was in the name of comte de Wardes.

Then, casting a glance on the handsome young man, who was barely twenty-five years old, and whom he left lying there, insensible and perhaps dead, he heaved a sigh over the strange destiny that leads men to destroy each other for the interests of people who are strangers to them and who often do not even know that they exist. ${ }^{1}$

The above extract portrays an incident of an attempted murder in such a light-hearted manner as if it were a demonstration of dexterity and fencing skills, an impromptu dance. The ghastly content of the story is masked so well by the cheerfulness of the narrative that danger appears thrilling and not really dangerous, wounds do not hurt and it does not hurt to wound. But this interpretation of fighting and injuring someone is clearly incorrect, as a normal, attractive person that d'Artagnan is supposed to be would not injure someone cheerfully and light-heartedly. Dumas obviously tampers with the idea of a swordfight in order to produce an image of it that amuses and entertains. In the Bergsonian terms, he breaks this idea down to its minute elements and reconstructs it to serve the needs of his narration, inevitably straying from the truth.

The description of a swordfight in The Chronicle of the Reign of Charles IX is more thorough, more distressing and more credible.

\footnotetext{
${ }^{1}$ Alexandre Dumas, The Three Musketeers, Translated by Richard Pevear, Penguin Books, 2006, pp. 216-217.
} 
Before Comminges could draw back his sward, Mergy struck him with his dagger on the head so violently that he himself lost his balance and fell to the ground. Comminges dropped at the same time, so that the seconds thought them both dead.

Mergy was soon on his feet, and his first motion was to pick up his sward which he had let slip in his fall. Comminges did not stir. Béville lifted him up, and wiping with a handkerchief his face, which was drenched in blood, saw that the dagger had entered the eye, and that his friend had been killed on the spot, the steel having beyond all doubt pierced the brain. ${ }^{2}$

Whereas d'Artagnan, leaving comte de Wardes to bleed, merely "heave[s] a sigh" and dashes off to continue his audacious expedition, Mergy "stare[s] at the corpse with haggard eyes." ${ }^{, 3 e}$ "shiver[s] all over, and great tears beg[i]n to trickle down his cheeks", which is a more plausible reaction to having killed a person than d'Artagnan's "heaving a sigh".

Despite defeating their adversaries, both men are themselves slightly wounded. When d'Artagnan's servant reminds his master of the wound, d'Artagnan says: "It's nothing. Let's deal with what's most urgent; then we can come back to my wound, which anyhow doesn't seem very dangerous to me." After that they ride off "with great strides." ${ }^{\prime \prime}$ Mergy, on the other hand, spends a few days convalescing and reflecting on his horrible experience, and Mérimée initiates us into his state of mind.

When you have killed a man, and when this man is the first you have killed, you are haunted for some time, and especially at nightfall, by the memory and the look of the last struggle that ushered in his death. The mind is so full of gloomy thoughts, that it is hard to take part even in the most trivial conversation; all talk wearies and annoys; while, on the other hand, solitude is dreaded because it strengthens the oppression of fancy. Despite the frequent visits of Béville and the captain, Mergy spent the days immediately succeeding his duel in the deepest sadness. A sharp touch of fever, brought on by his wound, kept him sleepless at night, and this was his worst time. ${ }^{7}$

Whilst reading Dumas' hilarious tale, we tend to skim the surface of the events. Reading Mérimée, we tend to become immersed in what is happening sharing the character's moods and

\footnotetext{
${ }^{2}$ Prosper Mérimée, A Chronicle of the Reign of Charles, translated by Frank S. Holby, New York and Philadelphia, MCMVI, pp. $144-145$.

${ }^{3}$ Mérimée, p. 145.

${ }^{4}$ Mérimée, p. 146.

${ }^{5}$ Dumas, p. 217.

${ }^{6}$ Dumas, p. 217.

${ }^{7}$ Mérimée, p. $151-152$.
} 
feelings as they may have taken place. Neither narrative is a perfect example of either simplification of reality or intuitive grasp, but each indicates a tendency towards one of the epistemological standpoints proposed by Bergson. Of course, Mérimée's story is also written with a certain purpose, and imaginary reality is selected and manipulated to produce a certain effect on the reader, but the author aims at giving a realistic account of Mergy's experiences and tries to initiate the reader into the mind of a duellist and let him or her learn how one really may feel after a successful contest. Whereas Dumas analyses, simplifies and distorts facts, Mérimée tries to follow them accurately in their complexity and originality, to intuit them.

Dumas' attention-grabbing narrative, where a series of crimes is skilfully presented as a string of breathtaking and enviable experiences, shows to what extent we can manipulate reality in our minds which, according to Bergson, happens in our interactions with reality all the time. Whilst perceiving something or someone, we present them to ourselves in the way that it fits with our wants, simplifying their nature, creating a one-sided picture of them and constructing an image exceedingly removed from the truth.

Are the problems in our communications due to the fact that we treat each other like Dumas treats d'Artagnan and comte de Wardes, without making an effort to understand what it is like to be someone else? Would the situation improve if we attempted to get into the heart of psychological events like Mérimée does? The Bergsonian answer would be yes, intuiting each other would bring harmony and happiness into society, and this paper tests the validity of this claim.

\section{The solitude of selfhood: from intelligence and instinct to intuition}

According to Bersgon, instinct and intelligence are not successive degrees of one and the same tendency but two qualitatively different epistemological tendencies that are linked to the practical needs of their agents. Animals need their instinct to direct them towards sources of food, and rationality is used to modify environment to suit the needs of human beings.

Intelligence looks at matter - and consequently at everything else - with the view of modifying it whilst building tools and thus regards it as a substance capable of adopting any form. There is a limit to 
what extent real matter can be decomposed and reassembled, but the mind disregards the matter's real limitations and treats it as decomposable in principle. Thus "the intellect is characterized by the unlimited power of decomposing according to any law and of recomposing into any system." (CE, 165)

We have seen in Dumas' example the unlimited agility of intellectual analysis where a horrific event is reworked to produce a hilarious tale. If necessary, the same event could be made into a funny, spooky or moving story, depending on the author's aim and regardless of the boundaries of the event itself. All this is possible because on the metaphysical level, "[t]he intellect represents becoming as a series of states, each of which is homogeneous with itself and consequently does not change." (CE, 171) If we attempt to reveal the internal change occurring within one of those states, we break it up into another series of states, and so on, so becoming and reality per se escape our understanding.

Instinct on the other hand can comprehend creation. It is moulded on the very form of dynamic life and, while intellect employs a mechanical approach to everything, instinct proceeds organically. The work of nature that creates organisms is, according to Bergson, continued in instinct, which is a natural ability to use an inborn mechanism. Instinct is a prolongation of the work of life and, if it were conscious, "it would give up to us the most intimate secrets of life." (CE, p. 174) Unfortunately, what is instinctive cannot be expressed in terms of intelligence, because instinctive activity is unconscious. Bergson concludes: "There are things that intelligence alone is able to seek, but which, by itself, it will never find. These things instinct alone can find; but it will never seek them.” (CE, p. 159)

Intuition appears on the scene as the epistemological faculty that transcends both intelligence and instinct and compensates for their deficiencies. Intuition is described as "instinct that has become disinterested, self-conscious, capable of reflecting upon its object and of enlarging it indefinitely." (CE, p. 186) An epistemological triumph over the rusty ways of our imperfect rational reasoning, the intuitive insight initiates our mind into the essence of the object, which makes intuitive knowledge independent from a subjective point of view. Whereas in analysis we remain outside the object and move round it, in intuition we use our imagination to immerse into the object. In analysis we break the object down to familiar elements and then attempt to reconstruct the original, but in intuition we coincide with the object as a whole. Thus intuition is a simple act, whilst the stages of analysis can go on indefinitely. Intuitive knowledge reflects the real, dynamic thing, superseding conceptual knowledge, which crystallizes the moving object into artificially constructed but practically manageable schemas and symbols. 
Bergson demonstrates the possibility of evoking intuition in the perception of motion. When we lift the arm, our mind, in its intelectual mode, does not imagine beforehand nor perceives "all the elementary contractions and tensions this act involves" but "is carried immediately to the end ... to the schematic and simplified version of the act supposed accomplished." (CE, pp. 315 - 316) The movement of the arm takes place by itself without the accompaniment of the conscious attention and fills the gaps between the imagined points of rest. To evoke an intuitive perception of this movement our consciousness must detach itself from the anticipated image of the completed act and concentrate on the movement that is going on at the time of perception. One must become aware of the immediacy and resist the temptation to reflect on the past phases and anticipate the following ones. As the movement unrolls, our conscious awareness must flow with it, coinciding with its unfolding. This would give us an immediate and uncontaminated insight into reality, disclosing to our mind duration as an indivisible fusion of successive moments. Unlike conceptual recognition, intuitive perception itself is a simple and indivisible act, the duplicate of duration, which it mirrors in an act of conscious awareness.

The exercise described above is within the range of human abilities and shows that intuition is attainable in principle. But if we can intuit the movement of one's own arm, does it follow that we can intuit conscious processes and thus enhance communication with fellow humans?

\section{Intuiting psychological duration}

Our misconception of concrete people and events stems from the deep-seated tendency to treat fleeting reality, including consciousness, as static things. If we could effortlessly intuit human consciousness, we would see it for what it is: a multiplicity of states that permeate one another and do not exist in separation. For example, we would not separate our being sad an hour ago and being happy now but we would recognise that our earlier state of mind contributes something to our later state of mind: perhaps an event that has made us smile now would not have made us smile had we not been sad previously.

An inner multiplicity, generated within consciousness, is distinct from extensive, measurable magnitudes found outside consciousness. An externally, spatially posited multiplicity contains countable units, whereas the inner multiplicity is a qualitative diversity and cannot be considered in 
numerical terms. Enumeration implies countable items, identical in nature but distinct from one another in their spatial position; otherwise they would merge into a single unit. Counting, Bergson argues, involves juxtaposition of units, setting them alongside one another - the procedure only being possible in space and not in time. Consciousness, on the other hand, belongs to the domain of time, "pure duration": this is the realm of the unextended and the intense. True time, consciousness, duration is "nothing but a succession of qualitative changes, which melt into and permeate one another, without precise outlines, without any tendency to externalise themselves in relation to one another, without any affiliation with number: it [is] pure heterogeneity.” (TFW, p.104)

Bergson asserts the dynamic self, which does not endure through time preserving some stable core of its identity - it is time in the way that it captures inner processes as they are and incorporates them into itself. Psychological duration is not a succession of clearly defined and mutually external units but is a heterogeneous continuity of qualitatively diverse successive phases ontologically bound with one another. There is no distinction between the duration itself and its content, and processes that constitute duration constitute embodied time in their ceaseless emergence.

We can intuit our own conscious processes if we stop thinking of our own self as made up of separate perceptions, memories and feelings and accept that our self is a continuous flux of interconnected processes, recognizing that "[t]here is a succession of states, each of which announces that which follows and contains that which precedes it" and that "[n]o one of them begins or ends, but all extend into each other.” (Introduction, p. 25)

We must let our consciousness fix its attention on the immediate phase of our psychological life without trying to name our current state, without reflecting on the past, however immediate, and without anticipating the future, however proximate. Our conscious awareness would then temporally coincide with the actual being of our psyche and follow emotions and sensations as they unfold. For Bergson, this is the only way we could grasp duration, which "can be presented to us directly in an intuition" and "can never ... be enclosed in a conceptual representation." (Introduction, p. 30)

Bergson asserts that primarily we do grasp our own conscious sates as they occur - permeating one another, melting into one another and forming an organic whole. Our feelings, perceptions, sensations emerge as ever changing and fluidic and only the necessity to rationalise and verbalise our conscious life brings about the edited, distorted picture of selfhood. We acknowledge our states of mind at the same time as they occur, but our thought does not remain dissolved in the emotional and sensual flux. 
Our orienteering in the world requires attention to the objects of thought, and if the object of thought is our own feelings, we need to pay attention to them. An attentive act takes some time, so if we focus on our inner psychological event that is happening at time $t$, our thought of it does not expire when the time $t$ passes. We continue pondering on the event that happened at time $t$ during time $t^{\prime}$, and our attentive act has inevitable side effects. Firstly, we miss events that happened after time $t$ and which are happening at time $t^{\prime}$. Secondly, our representation of time $t$ and of the events that happened at time $t$ is distorted because we no longer perceive these events in their fluidity. Rational attention, it seems, necessarily involves this misshapen perception of the world and people in it.

The primary experiencing of the self in its fundamental and most true form occurs in dreams, or in inattentive perception of sounds - in other words, at a pre-reflective stage, when the self lets itself relax. Then the self is detached from the external world and can just be itself without co-ordinating its fleeting elements with external markers. But as soon as we "wake up", we align the events of our inner life with the external phenomena, breaking duration into segments. It is extremely difficult to counteract the habitual way of dealing with our own self, but if successful, one is rewarded with the manifestation of one's own uniqueness and exclusivity. One gains a view of oneself where he or she is not measured or judged against any superimposed criteria and where one's value as an inimitable individual is not betrayed by standardisation.

The opposition of two epistemological faculties, intuition and analysis, involves two alternative ways in which human beings treat one another. We can either analyse, spatialise and simplify or intuit and understand. Although we spatialise each other under ordinary circumstances, one get a feeling that at least Bergson indicates an ideal philosophical model of communication. This ideal implies intuiting one's own and another person's selves in their purity, as durations and neutralizing antagonisms, which are due to the ignorance and estrangement between people.

But, as demonstrated in $T F W$, mind as duration can only be adequately accessed from within, by itself, and this makes one mind inaccessible for other minds. Bergson's example of Paul and Peter confirms the impossibility of grasping another person's true nature. (TFW, pp. 184 - 189) Paul, wishing to grasp Peter's state of mind, may learn all the facts about Peter's life and form an idea of his character. But this knowledge will necessarily be incomplete because when Peter passes through a certain psychic state, only he knows fully the intensity and the importance of this psychic state whereas Paul would reconstruct it by measurement or comparison. "[T] 
is nothing else than the feeling itself" (TFW, p. 185) and no amount of reconstructed information can replace the actual experiencing of that feeling firsthand. One can never be skilful enough to explain the importance of one's feelings to another person either, because the experienced state of mind is given to us directly "as an inexpressible quality” (TFW, p. 186) and our explanations will necessarily draw on argumentation and comparison. Our attempts to understand another mind by replacing real conscious experiences with symbols and images could only give us an accumulation of imperfect data, so the only way Paul could get to know Peter for real is by living Paul's life and feeling his feelings like an actor. The impersonation would have to be complete to minute details because "the most common-place events have their importance in a life-story”. (TFW, p. 187) But if Peter and Paul had the same experiences at the same time and in the same place, they could not be two separate people. They would be one and the same person who is Peter when he acts and Paul when he reiterates his history.

Our need for communication makes us spatialise duration. Bringing our conscious states outwards, we separate them from one another and express them in words, which is a precondition for communication. As Bergson admits, “[T] he intuition of a homogeneous space is ... a step towards social life" (TFW, p.138) and the clarity that the process of spatialization and externalisation of the self entails is essential for communication, whereas the truly genuine existence of selfhood is possible only in isolation from other selves.

Bergson concludes that the regular perception of one's own conscious life as duration would be only possible in a hypothetical individual who, immersed in his or her own being, would live a socially isolated life, where society and language would not force him or her to interpret his or her conscious flow as a series of individualised phenomena. (TFW, pp. $137-138)$ In its fundamental form the self is locked within itself and is incommunicable since any attempt to externalise psychic events involves their juxtaposition and spatialization.

Bergson's theory of duration and intuition leaves us with a disappointing result. After reading TFW, $\mathrm{MM}$ or $\mathrm{CE}$ one becomes convinced that the term duration illuminates some aspects of reality, which could otherwise be left unnoticed. Duration accounts for the continuity of temporal reality, heterogeneity highlights its complexity and its unity, and intuition is a process in which duration and heterogeneity are recognized as such. In the sphere of intersubjective relations intuition promises a deep mutual understanding that would remove the usual antagonisms based on the ignorance and rejection of other people's concerns and aspirations. But intuiting someone else in the Bergsonian 
sense would involve a complete identification with that person. One can only intuit one's own soul, but even that is not easy. Communication is based on conceptualisation and if the intuitive grasp of another mind were possible, it would involve a collapse of two individuals into one. Bergson's theory at this stage leaves us in a no win situation: people could have perfect relationships if they communicated as true selves, but in order to communicate at all, they must falsify their own and other people's nature. Bergson's theory of duration and intuition, instead of offering a model of perfect communication contradicts the very idea of communication as a valid social phenomenon. If we were hoping to receive guidance for finding happiness through the better understanding of each other, then what good is this ontologically illuminating but existentially pessimistic theory to us?

If in communication we seek mutual appreciation and the complete understanding of each other's nature then Bergson's theory of duration and intuition leads us to a dead end indeed. The ultimate harmony of intersubjective relations would require an absolute immersion into another person's mind, but if it were possible, it would be done at the expense of the privacy of our inner life, defying the sovereignty of our subjectivity and our psychological autonomy. But does this mean that intuition is not achievable in communication at all? Is loneliness the price that we must pay for our subjectivity and our psychological autonomy? It seems so if we understand communication in a narrow sense as a dialogue, where the parties stand face-to-face with one another and talk about each other, excluding from this discourse their wider interactions with the world. But if communication is not only an intense exchange of questions and answers about ourselves, then mutual understanding and intuition could be sought in joint action, in shared experiences, in creating and perceiving art, in teamwork, in belonging to a group, and other types of implicit, un-verbalised communication.

Bergson himself examines art as a form of communication where the artist communicates with the spectators via his or her intuitive creation, although this does not involve an exchange of personal data between the artist and the audience. (TFW, p 186) For Bergson, artistic creation is that ontological niche where human beings actualise their ability to intuit. Art connects the artist and the viewer, as both intuit the work of art, which is something other than their own personal history, something that belongs to both of them and at the same time exists independently from them. The same work of art may evoke different response in different viewers and it may be contrary to the artist's own disposition, but ontologically it will belong to the same unity as the artist's emotions, and will involve intuiting the same duration as the artist and other viewers. Thus the artist's personal input and the viewer's 
response are elements of one heterogeneity and as such are interconnected. By intuiting that unity, the viewer may feel the echo of the artist's presence, and the contemplation of the work of art may bring deep personal satisfaction through the artist's power of communication. The satisfaction may not necessarily be jovial. Art can move and disturb, but it gives us the feeling of mutual understanding that is distinct from the understanding of articulated concepts. In this intuitive understanding one accesses a psychological field other than existing within one's own mind but which echoes one's own mind. In art we intuit reality that others intuit too and this can give us a sense of belonging, comfort and inspiration, even though the belonging may be totally anonymous, as when listening to a piece of music by an unknown composer.

But what has been said about art can be said about any other act of communication. In art we have a materialised, definite manifestation of one person's being powerfully presented and making an impression on other people. Art is in its ideal form a disinterested activity, but any other communication also creates a field of shared experience not entirely reducible to a streamlined exchange of functional information. Every practical interaction is surrounded by a halo of personal touch where people appear unique and irreplaceable, even when they are treated as merely performing a certain function.

All Bergsonian characteristics of duration are applicable to instances of communication, we must conclude. Communication is an internally coherent process that has history and prehistory; it evolves and engages its participants in a flow of its own existence. We can treat communication as heterogeneous duration in its own right and the people's contributions to it as the elements of this heterogeneity. Then we can talk more positively of effective and satisfactory communication, as we realise that the boundaries of people's minds open up to one another if they are involved in the same process of communication.

\section{Communication as heterogeneous duration}

Communication underpins every instance of a joint purposeful action, and messaging is so intertwined with action that it would require a special investigation to establish at what point communication ends and action begins. This enquiry is not concerned with the relation of 
communication and action, but with the relations between communicating individuals, so we can overlook the difference between communication and action and let the two terms overlap.

Understanding communication in a wider sense than merely a verbal exchange that precedes some action, we could say that communication includes situations where individuals acknowledge a message and react to it. There may be a wide range of reactions, not excluding silence and inaction, for instance when students listen to a lecture. In this case the apparent inactivity of the contributors to the act of communication entails latent response and is a necessary component of that kind of communication. Indeed, the lecture as an act of communication requires a silent listening audience as well as the speaking lecturer, because if the lecturer is speaking in an empty room, it is not communication.

In the act of communication the interacting parties, whilst releasing and receiving information do not need to acknowledge each other. When reading a message we do not need to know who exactly wrote it. If we see a sign "Keep out" and do keep out, then the successful act of communication has taken place and the personality of the author is of little importance. Travellers passing through an uninhabited land would be excited to find any man-made objects - remains of a tent, or empty tins with an immediate feeling of having some communication with human beings who made and used those objects, although their names may never be known. Bergson himself talks of Robinson Crusoe providing an example where messages do not contain information about their authors and yet communication takes place. Robinson "remains in contact with other men" by means of "the manufactured objects he saved from the wreck". (TSMR, p. 16) These communications contain implicit messages of society encrypted in manmade objects conveying their manmade purpose and their manmade history. The manufacturers' role here amounts to being the carriers of that information. Their personalities are ontologically secondary and subservient to this flow of information, just as the elements of heterogeneity are subservient to the whole. What seems to be essential to communication is the meaningful fusion of the message and the response to it. The personalities of the individuals involved are secondary to this flow of content, as the participants can be left out of focus and yet the communication would still flow. What remains is the flow of content that relies on the conscious participants as conductors of information and as agencies that make ideas materialise.

Communication is generated by the joint conscious effort of its participants and in this sense it as a conscious process despite the fact that normally we think of a conscious process as the work of one mind. (Bergson teaches us to be flexible with our definitions and descriptions, convinced that it is 
better to violate and rework concepts, adapting words subtly to reality, than to ignore the intricacy of reality and squeeze it into an established conceptual framework. Bergson himself talks of degrees of consciousness in a different context ${ }^{8}$ but this approach justifies us attempting to explain the ambiguous reality of communication as conscious reality, although it is not conscious in the usual sense as belonging to one mind.)

It is essential for the nature of communication that it is generated by more than one people. It is made up of the acts of consciousness, which are released from their private, inaccessible mode of existence into the public domain. Externalised in a verbal form, conscious acts emanate from different subjects, interact and produce new psychological reality, which is a making of the contributing minds, of the combination of their verbally externalised thoughts. This makes it a psychological phenomenon without a subject that could perceive the whole process from the first person perspective.

The combining of thoughts cannot be controlled by either participant individually because the emanations come from different willing subjects. The process of communication is decentred, flows from one agent to another and, for the lack of the omniscient mind, evolves spontaneously, irrationally and involuntarily, at the same time appearing as an individualised and logically coherent event of a psychological kind.

Considered in the light of the traditional subject-object schema, the nature of communication is ambivalent because communication shows both objective and subjective features but is not quite either objective or subjective. On the one hand, facts of communication exist externally from one's mind and are recognised by other minds, and this makes them something objective. On the other hand, they exist only for conscious entities - subjects - and evaporate with their absence. This makes communication something subjective, something that is a product or a by-product of psychological activity.

When I communicate, I externalise my thoughts and they become less personal than when they were my inner thoughts. When I articulate them, I forfeit the confidentiality of my inner life, and I no longer have the sole possession of my thinking, which I have when I think my thoughts to myself. As I speak, I lose the authority over my thoughts and become subservient to my own words. Beginning to articulate my ideas, I commit myself at least to completing the sentence and to maintaining the train of thought that I initiated. I am also compelled to respond to the remarks and questions, which my statements evoke and in the course of the conversation I may even feel that the dialogue has drifted away from my

\footnotetext{
${ }^{8}$ See the discussion of living matter as containing features of consciousness. (CE, p. 80)
} 
original point and that I am not in command of its further development. Other participants are not in command of the dialogue either. The series of ideas moves forward by means of our unceasing contributions, but as there is no single author or editor that could censor it, adjust it and decide on its final form, it grows naturally, unedited and unrehearsed, all by itself. The narrative of the conversation bounces from one author to another and is constantly altered.

Radiating from the subjects, verbalised conscious states gain objective features. Thoughts that become words are accessible for perception and available for rational consideration and external scrutiny. They have an effect on the world and on their own speaker. But communication is not fully objective in the sense that it does not exist separately from conscious minds like physical objects do. Its mind independent existence amounts to the physical phenomena accompanying speech and writing but its existence as communication, an exchange of meanings vanishes if the minds that create it turn away from this exchange.

One could describe communication as the duration of conscious activity of a number of interacting individuals, typically externalised in a verbal form, but also possibly made up of gestures and including non-verbal signals. Externalised facts of consciousness - ideas, opinions, emotional responses, requests - and the replies that they receive amalgamate and produce a specific kind of intersubjective reality that gains some independence from its individual authors but depends on them for its existence.

\section{Communicating subjects as elements of heterogeneity.}

Instead of being authoritative subjects of communication, able to switch on and off dialogues and relationships, people have no sovereignty over these processes that they themselves initiate and maintain. We commit our rationality and our emotions to serving the flow of communication. On a minimal scale, if a question is asked, we are compelled to answer it. We may respond positively or negatively, but we naturally feel the urge to react, and refraining from reacting, ignoring a question, an accusation or an invitation may be harder than answering it.

When one is involved in the flow of communication, it can take over one's mind and one may be bound to continue that flow, to serve it. Engrossed in certain types of communication, one may not be able to stop this flow and break the ties that connect him or her with other conductors of that flow, 
because the flow is itself an internally coherent duration with its own drive to exist and to evolve by means of individual minds. The duration of communication is an enduring process asserting its own existence and resisting its own destruction, so the initiators and participants of romantic affairs, family circles, social groups instead of manipulating and manoeuvring these communications, let these communicative settings manipulate their minds, and become drawn into certain types of communication, captivated by them.

Involved in the flow of communication, we find it easier to support communication than to produce a response that hinders that coherent flow. We may find it easier to continue an unhappy relationship than to end it, we may struggle to stop a conflict or end an unpleasant conversation, even though we may know that our continuous involvement in this type of communication is damaging to us. Although communication is generated by the externalisation of people's conscious activity, in relation to all its participants it is independent reality that conditions their subsequent moves just as physical circumstances do. Communication acts in relation to its participants as an autonomous entity, which summons them to generate behaviour that would continue the given episode of communication. The very existence of a concrete communication is dependent on the activity of conscious participants but its ultimate content is autonomous from them and subdues those who create it.

Purposeful joint human activity generates its own duration that appropriates and absorbs the input of individual contributors. It can exist on a small or large scale and can amount to any social process: a conversation, meal, war, family, state. This conscious super-individual duration is initiated and maintained by individual people, but the same people who maintain its existence are dominated by it and must obey its principles. This manmade formation reflects on its creators and acts in relation to them as an independent, objective formation that dictates the rules and shapes their behaviour.

In the heterogeneity of communication not only the interacting people are its elements but the environment as well. Different circumstances contribute to different relationships because inanimate objects and our responses to them are part of the same duration as the people that communicate in these circumstances, because one does not communicate with a pure person detached from their surroundings. If we change the environment, the location where we meet and the way we dress, the nature of communication will change as well. For example, a holiday romance may blossom on a seaside, but die out if the lovers meet again in their home town, because their original interest in each 
other would not have been isolated from the feeling of liberty and bliss felt whilst sunbathing and splashing in the sea.

As elements of heterogeneity, we are not self-sufficient, and our identity is defined via relations with other participants of communication, via their actions, via their reactions to our performance. We lend a part of our being to a particular duration of communication, and that part, merged with the entire process, is intuited by others as part of the process that they intuit. That part of us is created and developed in interactions with other participants and they help create it and intuit it whilst creating it.

Engaging ourselves in communication, we channel the development of our being, which to some extent is developed in communication with the involvement of other people. Unaware of our past and of our life beyond the realm of our communication, they nevertheless participate in its creation while we communicate and they are able to intuit that part of our being that they themselves help to create.

\section{Intuition in communication}

Communication is duration in its own right, with its own internal structure, with strong ties between its phases, so the people involved in the process of communication are not the full masters of this process but are subservient to this process and are driven to sustain and complete communication in which they are involved. From this we may conclude that the success of communication does not necessarily equal the benefit and satisfaction of the contributors. Neither it equals the complete mutual understanding of the contributors. People may feel completely misunderstood and yet communication may still successfully evolve and result in some productive outcome which is not necessarily benign in relation to the people involved but is ontologically a coherent process. For example, a sad love story, destructive existentially for the people involved, is a complete and ontologically successful event. In a sense its participants must be unhappy or the character of this particular communication will be different. Also, if in communication we fail to understand each other, this does not necessarily mean the failure of communication, because we often communicate in order to achieve something else rather than specifically to understand each other's nature.

What is the role of intuition in communication? Is intuition an unrealistic solution of our epistemological problems whose significance is limited to being an ideal model of awareness, or, following Bergson, as a latent ability that can be developed and exercised? It seems that focusing on 
each other, no matter how intensely, would not give us the desired immersion into another person's soul. Any attempt to understand each other's nature is destined to failure, and the more intensely we focus on each other and obsess with the idea of mutual identification, the more we become frustrated, unable to express our inner nature sufficiently for another mind to achieve a complete sympathising with what they are. Two human beings facing each other remain individual durations. In fact, their facing each other reinforces the impenetrability of their being and secures the privacy of their fleeting thoughts and subtle feelings which, unedited and uncensored, can only appear inside one's own mind.

We have to agree that only the person himself or herself can intuit their inner being in full, but we find that the communicative whole is intuited by its participants who have the intimate and factual understanding of that duration from inside. A family member intuits his or her family not in the sense that he or she sympathises with and understands the uniqueness of each family member. He or she intuits the family as a dynamic system of relations created by its senior members at the point of marriage and recreated, reinforced and maintained by certain types of communicative behaviour by each member.

When we exchange messages, we acknowledge more than the factual information. We absorb masses of un-articulated information about our shared environment and experiences. If someone mentions Buckingham Palace to a person who had visited London, this evokes images of the specific atmosphere that surrounds the building, of British weather, of the crowds on the square. The imagery will be rich in content but instantly grasped, so that the conversing people would be intuiting the same thing and in this shared intuition they may find mutual understanding. It would be based on shared information that people do not articulate but which is assumed and which forms a background to their interactions.

The sense of mutual understanding can be achieved between the people who have a history of belonging to the same duration even if they had not met in person at that time, such as graduates of the same university, people of the same ethnic and cultural background, of the same age group and those who have similar problems. Under these circumstances people are intuited by one another not because they focus on each other and manage to perforate each other's minds but because they belong (partially) to the same duration in their past or present and see one another as participating elements. That part of their experiences which is left outside the shared sphere may find no response or understanding. For example, two women may sympathise with each other as mothers of young 
children, but if one of them has been in prison and another one has not, they could not share a sense of belonging when talking about that side of life.

This is a kind of understanding that can only be achieved by sharing experiences because the totality of any experience is too complex to translate into words and, say, a video recording would give a onesided visual and audio imagery, omitting olfactory and tactile images etc. The duration of shared experience or joint action is intuited only by those who create it and contribute to it.

In communication people intuit each other's involvement as heterogeneous elements of duration. It could be said that we intuit each other partially via intuiting the process of which we are part. In this sphere we gain a sense of intuitive belonging without forfeiting the privacy of our inner life, and this feeling of belonging can be achieved by simply being in the same environment as other people. Passengers on the plane, holidaymakers on the beach, students in the class - even if they do not exchange a single word, they know that they are exposed to the same risks and share the same goals as others in the group. The mere presence of other people who simply share the same time and place with us can be positive emotionally and existentially. One only needs to imagine a deserted beach or an empty airport with just one passenger to appreciate the social importance of human presence, unaccompanied by intelligent interactions but felt and intuited.

\section{Bibliography}

\section{Bergson's texts}

Henri Bergson, Creative Evolution, transl. Arthur Mitchell, Macmillan \& Co Ltd, London, 1964 (CE)

Henri Bergson, An Introduction to Metaphysics, transl. T. E. Hulme, Hackett Publishing Company, Indianapolis/Cambridge, 1999 (Introduction)

Henri Bergson, Matter and Memory, transl. Nancy Margaret Paul and W. Scott Palmer, Zone Books, New York, 1991. (MM)

Henri Bergson, Time and Free Will: An Essay on the Immediate Data of Consciousness, transl. F.L. Pogson, London, George Allen and Unwin, 1910 (TFW)

Henri Bergson, The Two Sources of Morality and Religion, transl. R. Ashley Audra and Cloudesley Brereton, University of Notre Dame Press, Notre Dame, Indiana, 1986 (TSMR)

\section{Original French publications}

Henri Bergson, L'évolution créatrice. Paris: Presses Universitaires de France, 1907 
Henri Bergson, Essai sur les données immédiates de la conscience. Paris: Presses Universitaires de France, 1889

Henri Bergson, "Introduction à la métaphysique” in Revue de Métaphysique et de Morale, January, 1903

Henri Bergson, Matière et mémoire. Paris: Presses Universitaires de France, 1896

Henri Bergson, Les deux sources de la morale et de la religion. Paris: Presses Universitaires de France, 1932

\section{Other texts}

Alexandre Dumas, The Three Musketeers, Translated by Richard Pevear, Penguin Books, 2006

Prosper Mérimée, A Chronicle of the Reign of Charles, translated by Frank S. Holby, New York and Philadelphia, MCMVI 